\title{
LA CORTE SUPREMA DE JUSTICIA DE LA NACIÓN PROFUNDIZA RESTRICCIONES A LA LIBERTAD SINDICAL EN TIEMPOS DE EMERGENCIA OCUPACIONAL
}

\begin{abstract}
Franco Giavedoni ${ }^{1}$
Sumario: I.- El precedente "Laurenzo, Juan Manuel C/ Unión Platense S.R.L. s/ amparo sindical". La plataforma fáctica y la resolución de la CSJN. II.- La normativa de crisis vinculada a proteger el empleo. Precedentes jurisprudenciales de relevancia. III.- Restricciones a la reinstalación sindical. El criterio de oportunidad en el precedente de la CSJN "Laurenzo". IV.- Reflexión final. Necesidad de realizar un análisis ab initio de la causal extintiva.
\end{abstract}

Resumen: I.- El precedente “Laurenzo, Juan Manuel c/ Unión Platense S.R.L. S/ amparo sindical". La plataforma fáctica y la resolución de la CSJN. II.- La normativa de crisis vinculada a proteger el empleo. Precedentes jurisprudenciales de relevancia III.- Restricciones a la reinstalación sindical. El criterio de oportunidad en el precedente de la CSJN “Laurenzo". IV.- Reflexión final. Necesidad de realizar un análisis ab initio de la causal extintiva.

Palabras clave: Emergencia. Despidos. Reinstalación. Restricciones. Oportunidad

I.- EL PRECEDENTE “LAURENZO, JUAN MANUEL C/ UNIÓN PLATENSE S.R.L. S/ AMPARO SINDICAL". LA PLATAFORMA FÁCTICA Y LA RESOLUCIÓN DE LA CSJN

El presente análisis se centra en el precedente de la CSJN: "Laurenzo, Juan Manuel c/ Unión Platense S.R.L. s/ amparo sindical" dictado el pasado 4 de junio de 2020.

En el precedente citado, el actor Sr. Juan Manuel Laurenzo se desempeñaba como chofer de la empresa Unión Platense S.R.L. siendo despedido con invocación de causa en los términos del art.242, LCT.

En función de ello, el actor inició acción de amparo sindical persiguiendo que se declara-

1 Abogado egresado de la Universidad Nacional de Córdoba, distinguido con el Diploma al Mérito por la Facultad de Derecho y Ciencias Sociales de la Universidad Nacional de Córdoba; Especialista en Derecho Laboral (convenio UNC-UCC-UNL), asesor sindical. Dirección de E-mail: giavedoni_f@hotmail.com. 
se nulo el despido, se dispusiera su reincorporación y se le abonasen los salarios caídos. Sostuvo que revestía la condición de miembro de la comisión organizativa de la seccional La Plata de la Unión de Conductores de la República Argentina (U.C.R.A.) y que la rescisión era nula por discriminatoria en tanto fue despedido por razones gremiales.

Para fundar su pretensión el actor sostuvo que al ser designado miembro de la comisión organizativa de la seccional La Plata de la U.C.R.A., suscribió con otras cinco personas un acta que derivó en que por lo menos cuatro de los firmantes han sido objeto de despidos a la postre judicializados como discriminatorios.

Como medida cautelar solicitó que se deje sin efecto el despido y que se ordene la reinstalación.

El Tribunal del Trabajo $\mathrm{N}^{\circ} 2$ de La Plata admitió la medida cautelar solicitada y ordenó reinstalar al trabajador hasta el dictado de sentencia definitiva sobre el fondo de la cuestión.

Contra dicha decisión la demandada dedujo recurso de reposición y, subsidiariamente, recursos extraordinarios de nulidad e inaplicabilidad de la ley.

El primer recurso fue rechazado y la concesión de los recursos restantes fue denegada. La empresa se presentó en queja ante la Suprema Corte de Justicia de la Provincia de Buenos Aires y dicha presentación también fue desestimada. Para así resolver, el tribunal cimero provincial sostuvo que, según doctrina de esa Suprema Corte, "las decisiones relativas a las medidas cautelares no revisten carácter de definitivo en los términos del art. 278 del-1- Código Procesal Civil y Comercial".

Agregó que no se observaban motivos que permitiesen apartarse de dicha regla.

Contra tal pronunciamiento la empresa demandada interpuso recurso extraordinario que, denegado, dio origen a la queja en examen.

La demandada, sostuvo entre sus principales argumentos recursivos:

- Que la decisión de reinstalación era equiparable a una sentencia definitiva porque anticipaba la solución de fondo e irrogaba graves daños en lo económico, social y empresarial;

- Que la medida precautoria implicaba forzar al empleador a asignar y a confiar unidades de transporte público de pasajeros a alguien en quien no puede depositar su confianza. - Que las facultades de organización y dirección del empleador, en particular las disciplinarias, no podrán ser ejecutadas adecuadamente.

- Que se estaba afectando gravemente su libertad de contratar en tanto no solo se fuerza el reingreso de un trabajador despedido sino que se obliga al empleador a mantenerlo en su puesto sin plazo cierto, independientemente de la conducta que despliegue.

- Para ilustrar la gravedad de la afectación a su libertad de contratar, la demandada invocó los argumentos de la disidencia de los jueces Lorenzetti, Highton de Nolasco y Argibay en autos "Álvarez, Maximiliano y otros c/ Cencosud".

En dicho precedente se dispuso la aplicación de la ley 23.592 en el marco de las relaciones laborales posibilitando la declaración de ineficacia del acto considerado discriminatorio equiparándolo al acto jurídico de objeto prohibido (art. 953 del Código Civil) o, inclu- 
so, a la figura del abuso del derecho (art. 1071 del Código Civil). De modo que la rescisión decidida por la empleadora no tendría eficacia en razón de su finalidad discriminatoria.

Sin embargo, la minoría citada sostuvo argumentos diferentes en orden a armonizar el derecho humano afectado por el acto discriminatorio con el derecho constitucional referido a la libertad de contratación. Así se sostuvo que: "Ia libertad de contratar integra en nuestro ordenamiento el complejo de la libertad como atributo inherente al concepto jurídico de persona, y -en principio-comporta la posibilidad de elegir la clase de comercio que más conviniese a su titular y la de ejecutar los actos jurídicos necesarios para el ejercicio de ese comercio. En el ámbito del contrato de trabajo esta libertad de contratar se encuentra reglamentada por normas de carácter imperativo que generan restricciones al contenido de la relación laboral, es decir, a las condiciones a las que está sujeta dicha relación. Al respecto, la garantía constitucional a la libertad de contratar incluye su aspecto negativo, es decir, la libertad de no contratar que es un aspecto de la autonomía personal a la que todo ciudadano tiene derecho (art. 19 de la Constitución Nacional) y un supuesto del derecho a ejercer una industria lícita (art. 14 de la Constitución Nacional). Que en esta línea, este Tribunal ha señalado que no se puede obligar a un empleador - contra su voluntad-a seguir manteniendo en su puesto a empleados que no gozan de la confianza que debe presidir toda relación de dependencia. También manifestó que una vez rota la relación laboral a raíz de un despido injusto se debe reconocer al trabajador el derecho a reclamar una indemnización razonablemente proporcionada al perjuicio sufrido (conf. doctrina de Fallos: 273:87, De Luca, 306:1208, Figueroa y 321:3081, Agnese).

Cabe aclarar que en el precedente "Álvarez" se trataba de un despido sin invocación de causa donde la estabilidad estaba fijada con un límite temporal equivalente al mandato más un año.

En el precedente bajo análisis la reinstalación tendría lugar mientras dure el litigio sobre el fondo de la cuestión, sin plazo cierto.

\section{LA RESOLUCION DE LA CORTE SUPREMA DE JUSTICIA DE LA NACION}

La C.S.J.N., en fallo dividido, sostuvo que si bien es cierto que el análisis de cuestiones procesales como las propuestas por la apelante es ajena al ámbito del recurso extraordinario, cabe apartarse de tal regla cuando la disposición adoptada frustra la vía utilizada por el justiciable sin fundamentación idónea suficiente, defecto que se traduce en una violación de la garantía del debido proceso tutelado en el artículo 18 de la C.N.

Dicho esto, la C.S.J.N. observó que el Tribunal a quo no consideró que el hecho de que la medida precautoria anticipe la solución de fondo ordenando la reinstalación del trabajador puede ocasionar agravios de difícil o imposible reparación ulterior que justifican considerar que la decisión es equiparable a definitiva.

Por tales motivos se resolvió la habilitación de día y hora inhábil a los fines del dictado de la sentencia y hacer lugar a la queja, declarando procedente el recurso extraordinario y dejando sin efecto la sentencia apelada que ordenaba a la demandada la reinstalación del trabajador despedido.

En disidencia los Dres. Maqueda y Rosatti sostuvieron que el recurso extraordinario, cuya denegación dio origen a la queja, no se dirige contra una sentencia definitiva o equiparable a tal (artículo 14 de la ley 48). 


\section{II.- LA NORMATIVA DE CRISIS VINCULADA A PROTEGER EL EMPLEO. PRECEDENTES JURISPRUDENCIALES DE RELEVANCIA}

En vistas de que el 11 de marzo de 2020 la Organización Mundial de la Salud (OMS) declaró el brote del nuevo Coronavirus como una pandemia, el Gobierno Nacional dispuso la adopción de medidas con el fin de mitigar su propagación e impacto sanitario.

Sin embargo, cabe aclarar que la declaración de la emergencia sanitaria tuvo lugar en un contexto nacional de crisis generalizada y preexistente a la pandemia.

Huelga recordar que mediante decreto 34/2019 ya se había declarado la emergencia ocupacional y mediante la ley 27.541 se estableció la emergencia pública en materia económica, financiera, fiscal, administrativa, previsional, tarifaria, energética, sanitaria y social.

En este contexto, tuvo lugar el dictado del DNU N 329/2020 y su posterior prórroga DNU $487 / 2020$.

Mediante ellos se estableció una suerte de estabilidad reforzada en el empleo privado con el fin mitigar los efectos nocivos de aquella crisis generalizada y preexistente garantizar la conservación de los puestos de trabajo por un plazo razonable.

Así las cosas, se prohibieron los despidos sin justa causa y por las causales de falta o disminución de trabajo y fuerza mayor. De igual modo se prohibieron las suspensiones por las causales de fuerza mayor o falta o disminución de trabajo.

A los efectos de garantizar la eficacia de tales medidas se dispuso que los despidos y las suspensiones que se dispongan en violación de los citados decretos no producirán efecto alguno, manteniéndose vigentes las relaciones laborales existentes y sus condiciones actuales.

Ello motivó a nivel jurisprudencial una gran cantidad de precedentes en todo el país que dispusieron, con fundamento en las disposiciones reseñadas, la reinstalación de trabajadores despedidos durante la vigencia de la prohibición realizando incluso, en algunos supuestos, una aplicación "antifraude" de la prohibición de despedir.

Entre los precedentes mencionados pueden reseñarse:

1) La sentencia número 43 de fecha 19/5/2020 dictada en autos: "Zampetti Allende, Rubén Darío C/Jbg Group S.A. - Medida autosatisfactiva"(Expediente N9197978) donde se ordenó la reinstalación de un trabajador despedido por fuerza mayor luego de publicado en el Boletín Oficial el DNU 329/2020. En el fallo se sostuvo que el DNU 329/20 ha privilegiado la contención social de las fuentes de trabajo en este escenario de peligro modificando transitoriamente previsiones de derecho laboral común en materia de despido;

2) El precedente "Sánchez Candela C/ Lapenta Srl - Medida Autosatisfactiva", dictado por el Juzgado de Conciliación Nº del 5/6/2020 donde se ordenó la reinstalación de un trabajador desvinculado sin causa durante la vigencia de la prohibición de despedir.

3) La sentencia en autos "Romero Sharon Patricia C/ Mm Directa S.A." del Tribunal del Trabajo No 1 de San Miguel (Bs. As.) de fecha 4/6/2020 que dispuso la reinstalación de una trabajadora despedida por abandono de trabajo en el marco de un medida cautelar innovativa justificando tal decisión en el hecho de que "no se advierte prima facie el silencio" que invoca la empresa para despedir.

4) El precedente "Coppola Leonardo Lucas C/ Instituto Nacional de Servicios So- 
ciales para Jubilados y Pensionados - Medida Cautelar", del Juzgado Nacional del Trabajo $N^{\circ} 54,22 / 5 / 2020$, donde se ordenó reinstalar a un trabajador despedido sin expresión de causa aplicando la "teoría de la recepción" en materia de notificaciones dado que si bien la fecha de emisión del despido era anterior al DNU que los prohíbe su recepción fue posterior.

5) La sentencia dictada por la Cámara Nacional de Apelaciones del Trabajo, Sala IX, en la causa N 10206/2020, “Chávez, Bianca Magalí c/ 25 HORAS S.A. - s/Medida cautelar" mediante la cual se ordenó reinstalar a una trabajadora despedida durante el período de prueba con fundamento en la violación del DNU 329/2020.

6) El precedente dictado por el Juzgado de Conciliación de $2^{\text {a }}$ Nom. de Río Segundo en autos "Duarte, Daniel Adán CI Oscar Scorza Equipos Y Servicios SRL- Expediente: 9186013" mediante el cual se realizó un análisis ab initio de la causal de despido invocada por la demandada.

Sostuvo el Tribunal la necesidad de analizar en forma previa si existe "verosimilitud del derecho" invocado para concluir, luego incluso de producir prueba testimonial, que la causa invocada no sería la "real" y por lo tanto se habría producido una violación al decreto 329/2020.

Esta verosimilitud se desprende tanto por la "generalidad" de los términos de la causal invocada como despido, como también de la prueba recepcionada en el marco del art. 457 del CPC.

Como puede advertirse la jurisprudencia se ha inclinado por una respuesta jurisdiccional en la emergencia anticipando incluso el análisis y apreciación de la suficiencia -o no- de la expresión de los motivos que originaron el distracto, dado que de lo contrario, dicho análisis llegaría irremediablemente tarde si es abordada recién en la sentencia de fondo y luego de un trámite prolongado.

Como sostiene Sebastián Coppoletta: "Si en los próximos 60 días, una persona es despedida en violación al art. 2 del DNU 329/2020 -ojalá que no- y deja de devengar y percibir salario, entonces el muy buen y justo juicio laboral que culmine en una excelente sentencia adecuadamente fundada y que disponga la nulidad del despido, la reinstalación y el pago de los salarios devengados y no percibidos dictada dentro de....¿2, 3,..5 años? no será la respuesta jurídica adecuada a la actual situación de necesidad y urgencia que justifica el DNU².

\section{III.- RESTRICCIONES A LA REINSTALACIÓN SINDICAL. EL CRITERIO DE OPORTUNIDAD EN EL PRECEDENTE DE LA CSJN “LAURENZO”.}

Son pocos los casos en los que se aporta un concepto de libertad sindical con vocación de generalidad y abstracción de todo marco normativo.

No obstante, una aproximación al concepto basada en la legislación nacional es la que aporta Etala quién sostiene que la libertad sindical es el conjunto de derechos, potestades, privilegios e inmunidades otorgados por las normas constitucionales, internacionales y legales a los trabajadores y las organizaciones voluntariamente constituidas por ellos para garantizar el desarrollo de las acciones lícitas destinadas a la defensa de sus intereses y al mejoramiento de sus condiciones de vida y de trabajo ${ }^{3}$.

2 Ver "DNU 329/2020: una oportunidad para que se luzca el Derecho Procesal del Trabajo... y las juezas y los jueces que lo apliquen" por Sebastián Coppoletta, en Dossier 3 del Suplemento Digital de la Revista de Derecho Laboral Actualidad, "El impacto del coronavirus en las relaciones laborales", www.rubinzalonline. com.ar, RC D 1536/2020.

3 ETALA, Carlos Alberto, Derecho Colectivo de Trabajo, Astrea, Buenos Aires, 2001, p. 59. 
La libertad sindical, entendida como un derecho subjetivo individual y colectivo presenta una doble dimensión que le otorga un contenido complejo dado que supone expresiones individuales de los trabajadores o empleadores y expresiones colectivas propias de las organizaciones que aquellos constituyan. Así puede hablarse de una doble dimensión, individual y colectiva.

En el precedente que se comenta la CSJN ha dado una clara señal restringiendo la libertad sindical individual en un contexto de crisis generalizada, no solo sanitaria sino también ocupacional.

En este sentido, se profundiza una tendencia ya advertida en el precedente "Orellano, Francisco Daniel c/ Correo Oficial de la República Argentina S.A." vinculado a la autonomía sindical de orden colectivo.

Sin embargo, en el caso bajo análisis, no puede dejar de mencionarse el contexto en que se dicta el pronunciamiento, lo que conlleva un criterio de oportunidad ejercido por la CSJN mediante el cual se está limitando la aplicación extensiva y "antifraude" realizada por numerosos tribunales del país en aquellos casos de reinstalación por vía cautelar de trabajadores desvinculados con causa, anticipando de esta manera la resolución de fondo con riesgo de ocasionar un perjuicio de imposible o muy difícil ulterior reparación.

\section{IV.- REFLEXION FINAL. NECESIDAD DE REALIZAR UN ANÁLISIS AB INITIO DE LA CAU- SAL EXTINTIVA}

Mientras se escriben estas páginas múltiples datos alertan sobre el avance de una crisis económica sin precedentes, expresada en el aumento del desempleo, la desvalorización de nuestra moneda, la suba del peso de la deuda externa sobre nuestro presupuesto o el diario incremento de la pobreza y la indigencia.

En este sentido, considero desafortunado el precedente que se comenta dado que, frente a un sector empleador que transita por una situación económica compleja y apremiante, habido por reducir costos, entre ellos los laborales, la única posibilidad con la que cuenta el trabajador para hacer cumplir la normativa de emergencia es a partir de su reconocimiento jurisprudencial.

Será entonces tiempo de extremar el análisis jurídico de los hechos narrados para imposibilitar la evasión a la prohibición temporal de despido y para ello, se torna imperioso el examen liminar del intercambio telegráfico por parte de los jueces a los que les toque intervenir.

Deberá exigirse un análisis ab initio sobre los términos y condiciones en que se ha configurado el distracto a los fines de establecer si se cumple o no con la exigencia de indicar de manera detallada y autosuficiente la conducta injuriosa imputada al dependiente, so pena de consentir una evasión artera al sistema de protección ideado para este momento de marcada incertidumbre económica y social generada por el avance del COVID-19. En palabras del precedente que se comenta, si así no se hiciera, se corre riesgo de ocasionar un daño de imposible o muy difícil reparación ulterior precisamente a quién resulta sujeto de preferente tutela constitucional, es decir el trabajador. 